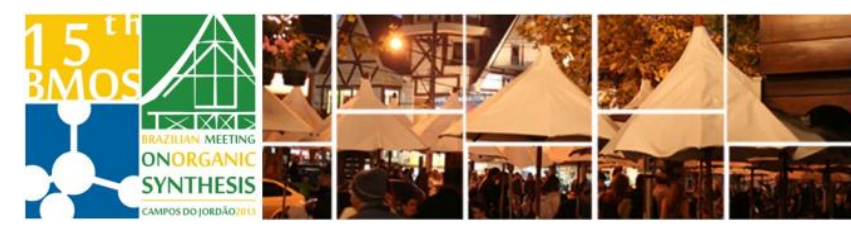

\title{
Synthesis and photophysical studies of a chlorin sterically designed to prevent self-aggregation
}

\author{
Francisco F. de Assis, Juliana M. de Souza, Beatriz H. K. Assis, Timothy J. \\ Brocksom, Kleber T. de Oliveira*
}

Universidade Federal de São Carlos - UFSCar, Departamento de Química, 13565-905, São Carlos, SP, Brazil. *e-mail: kleber.oliveira@ufscar.br; www.lqbo.ufscar.br

Keywords: Chlorin, Photodynamic therapy, Low aggregation.

\section{INTRODUCTION}

Chlorins are obtained by reduction of one double bond at the $\beta$ position of the porphyrin ring (Figure 1).

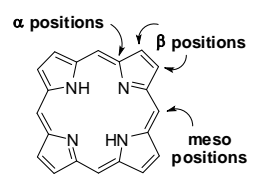

Porphyrin ring

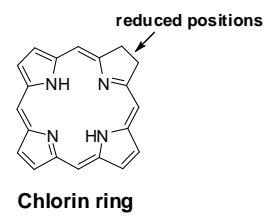

Figure 1. Porphyrin and chlorin core structures.

The chlorins exhibit a strong absorption band around $660 \mathrm{~nm}$, which suggests use in photodynamic therapy (PDT). ${ }^{1}$ Due to the extended conjugated core structure, they often suffer self-aggregation, which is a negative point for application in PDT. In this work, we have prepared a new chlorin derivative which is self-prevented from aggregation, by a 1,3dipolar cycloaddition between a very activated porphyrin (dipolarophile) and a benzyl azomethine ylide. ${ }^{2}$ We have also performed some preliminary photophysical studies in order to evaluate its ability to act as a photosensitizer in PDT.

\section{RESULTS AND DISCUSSION}

Our approach started from pyrrole 2, prepared from diethyl fumarate (1) and p-toluenesulfonylmethyl isocyanide (TosMIC) in $71 \%$ yield (Scheme 1). Compound 2 was used as the building block in the synthesis of porphyrin 4, utilizing trioxane (3) and TFA (Scheme 1). A 1,3-dipolar cycloaddition reaction was then performed with porphyrin 4 , using benzyl azomethine ylide $\mathbf{6}$, generated in situ from trioxane (3) and $\mathrm{N}$-benzylglycine hydrochloride (5). Chlorin 7 was obtained in $18 \%$ yield after purification by preparative TLC. Aggregation studies were carried out using two different techniques: UV-Vis and ${ }^{1} \mathrm{H}$ NMR. Measurements were performed in different concentrations using chloroform as solvent. In the NMR studies, the range of concentrations was much higher than for the UV-Vis analysis, and even in that case, chlorin 7 exhibited no aggregation (Figure 2).

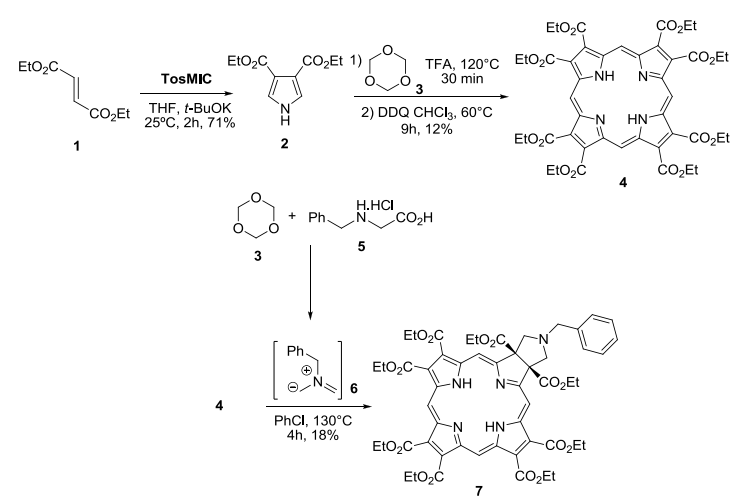

Scheme 1. Synthesis of chlorin 7

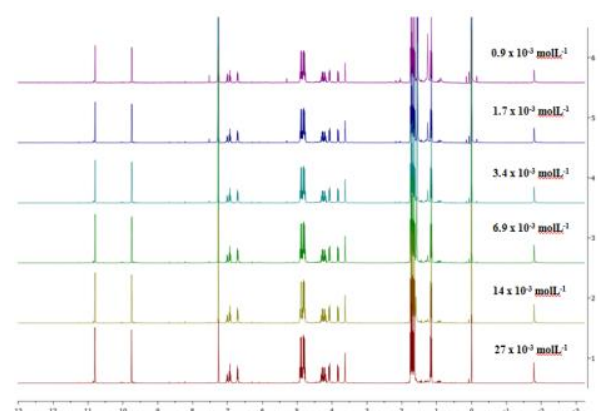

Figure 2. Aggregation studies by ${ }^{1} \mathrm{H} \mathrm{NMR}$ in $\mathrm{CDCl}_{3}$.

Other measurements such as singlet oxygen production, fluorescence yield, and photo degradation studies were also performed, providing good results as demonstrated in our recent publication in Dyes and Pigments. ${ }^{2}$

\section{CONCLUSION}

We conclude that chlorin $\mathbf{7}$ is a good candidate for PDT studies, due to its low-aggregation character and very good photophysical properties for PDT studies.

\section{ACKNOWLEDGEMENTS}

The authors thank FAPESP (2013/06532-4, 2012/24098-4, 2011/13993-2), CNPq and CAPES for financial support and fellowships.

\section{REFERENCES}

${ }^{1}$ Ethirajan, M.; Chen, Y.; Joshi, P.; Pandey, R. K. Chem. Soc. Rev. 2011, 40,340 .

${ }^{2}$ de Assis, F. F.; de Souza, J. M.; Assis, B. H. K.; Brocksom, T. J.; de Oliveira, K. T. Dyes and Pigments 2013, 98, 153. 